\title{
Е.Ф. Киреева
}

\section{НАЛОГООБЛОЖЕНИЕ ЦИФРОВОГО БИЗНЕСА В БЕЛАРУСИ: НОВЫЕ ПОДХОДЫ И СТИМУЛИРУЮЩИЕ МЕХАНИЗМЫ}

\begin{abstract}
В статье рассматриваются проблемы организации налогообложения бизнеса в условиях развития е-рынка. Определяется понятие е-бизнеса, необходимость оценки емкости е-рынка с иелью разработки стратегии развития электронной торговли и услуг. Обобщены налоговые механизмы по осуществлению деятельности в сфере производства и торговли ИКТ. Рассмотрены особенности налогообложения оказания электронных услуг нерезидентами в Беларуси. Проанализированы налоговые и правовые стимулы для резидентов Парка высоких технологий. Предложены варианты развития налогового законодательства для электронного бизнеса.

Ключевые слова: электронный бизнес, электронные услуги, налогообложение, е-рынок, налогообложение электронных услуг, Парк высоких технологий, налоговые льготы.
\end{abstract}

Глобализация и цифровизация всех процессов жизнедеятельности общества привлекли пристальное внимание к исследованию этой проблемы ученых в различных областях, в том числе и в сфере экономики. Определение и концепция электронной экономики появились в последнем десятилетии XX в. Из первых цитируемых публикаций, определивших понятие цифровой экономики (digital economy), можно выделить работы канадского экономиста Дона Тапскотта [1]. Бурное развитие ИТ-технологий и их внедрение в цифровую экономику выделило направление научных исследований именно в этой области.

Необходимо отметить, что определение цифровой экономики и включение в нее отдельных компонентов находятся в постоянном развитии в связи с активизацией процессов и формированием новых бизнес-моделей. Наиболее примечательными на наш взгляд являются научные публикации, в которых выделены отдельные структурные элементы цифровой экономики: цифровые продукты, услуги, производство, основанное на информационно-коммуникативных технологиях (ИКТ). Например, это статьи Роба Клинга и Роберта Лэмба [2], а также работы Томаса Л. Мезенбурга [3], рассматривающие цифровую экономику как совокупность производства ИТ-технологий и использование ИТ-технологий для бизнеса.

Расширение экономической деятельности, связанной с цифровыми технологиями, определяет в качестве приоритетных задач необходимость измерения цифровой экономики как для анализа, так и с целью государственного регулирования. В статье Р. Букха, Р. Хикса «Определение, концепция и измерение цифровой экономики», посвященной этой проблема- 
тике, в обобщенном виде анализируются различные подходы и методы в определении объема цифровой экономики [4].

Анализ современных публикаций по этой тематике позволил выдвинуть научную гипотезу о необходимости изучения феномена цифровизации бизнеса в национальном сегменте как с точки зрения его оценки, так и применения стимулирующих механизмов, в том числе и налоговых.

В процессе подготовки статьи был использован комплекс методов экономических исследований, объединенных системным подходом к изучению проблемы: аналитический, монографический, экономико-статистический.

Активное развитие цифровых технологий оказало существенное влияние на происходящие экономические процессы в мировой экономике, значительно облегчило внедрение национальных экономик на глобальный рынок.

В условиях ограниченности ресурсов е-бизнес становится драйвером экономического прогресса и обеспечивает рост инноваций, высоких технологий, функционирование рынка во всех его проявлениях и формах, в том числе путем цифровизации не только экономических, но и социальных процессов.

Цифровая среда, в свою очередь, является важным условием его развития, по сути, новым и перспективным направлением, сокращающим физические транзакционные издержки и глобализирующим экономическую деятельность.

В отечественной экономической и юридической литературе определение е-бизнеса не имеет однозначного толкования. Учитывая особенности технологических и бизнес-процессов с определенной долей условности, ебизнес можно разделить на бизнес IT-отрасли и бизнес, использующий сервисный информационный ресурс в качестве организации традиционного бизнеса.

Глобальное распространение в мировой экономике е-бизнеса основывается на наличии определенных преимуществ использования ИТтехнологий в предпринимательском секторе: гибкость и мобильность безбарьерного рынка, использование преимуществ налоговой конкуренции различных юрисдикций, экономия на транзакционных издержках; высокая доходность и конкурентоспособность и др.

Эти преимущества и явились толчком для быстрого роста цифровой экономики, которая базируется на новых технологиях обработки и передачи информации, а также на сетевом характере организации бизнес-моделей.

На сегодняшний день это огромный рынок. По предварительной оценке международной исследовательской и консалтинговой компании, занимающейся изучением мирового рынка информационных технологий и телекоммуникаций, International Data Corporation (IDC) к 2022 г. более 60\% глобального ВВП будет поступать от цифровых технологий и решений [5]. В 2018 г. объем мирового рынка информационно-коммуникационных технологий составил \$4 трлн, общий объем продаж интернет-коммерции по всему миру подбирается к \$2 трлн [6]. 
Такие темпы роста е-бизнеса не могут не рассматриваться как перспективное направление для роста любой национальной экономики, и Беларусь не исключение.

На наш взгляд, базовыми условиями развития е-бизнеса в любом регионе, и как следствие, необходимости привлечения к нему внимания со стороны государства является оценка потенциала рынка и потенциала возможностей бизнеса, а также условий и среды, обеспечивающих это развитие (табл. 1).

Таблииа 1. Базовые условия развития е-бизнеса [7]

\begin{tabular}{l|l}
\hline \multicolumn{1}{c|}{ Условия } & \multicolumn{1}{c}{ Среда $^{1}$} \\
\hline Доступность ИКТ (в том числе ценовая) & $\begin{array}{l}\text { Сеть Интернет (подключение } \\
\text { и использование) }\end{array}$ \\
\hline $\begin{array}{l}\text { Использование ИКТ } \\
\begin{array}{l}\text { Навыки в сфере ИКТ (интернет- } \\
\text { грамотность) }\end{array}\end{array}$ & Пнфраструктура ІТ-отрасли \\
\hline $\begin{array}{l}\text { Правовое обеспечение деятельности в сфере } \\
\text { ИКТ }\end{array}$ & Кадры системы \\
\hline
\end{tabular}

Республика Беларусь достигла значительных успехов в развитии ИКТ, что свидетельствует о возможности совершенствования е-бизнеса на ее территории. В соответствии с глобальным рейтингом развития ИКТ Беларусь заняла 32-е место и лидирует среди стран ЕАЭС, далее следует Российская Федерация - 44-е место, Казахстан - 52-е место, Армения 75-е место и Кыргызстан - 109-е место среди обследуемых стран мира. Индекс развития ИКТ в Беларуси близок к среднему по группе стран с высоким доходом, однако отстает от лидера рейтинга, Исландии - на 16\% [8].

Немаловажное значение для функционирования е-бизнеса имеет и развитие IT-сектора, с одной стороны, как его части, с другой - как инфраструктуры для е-торговли. Согласно рейтингу Global Services 100 Беларусь находиться на 13-й позиции среди 20 стран-лидеров в сфере ИТаутсорсинга и высокотехнологичных услуг.

Беларусь входит также в число стран-мировых лидеров по экспорту ITуслуг на душу населения. На долю ИКТ приходится 10,5\% ВВП в секторе услуг и 5,1\% от общего ВВП Беларуси [9].

Можно отметить, что, несмотря на достаточно динамичное развитие ITсектора и высокий индекс ИКТ в Беларуси, эта сфера находится на начальном этапе и в основном ориентирована на реализацию продуктов и услуг на наиболее продвинутые западные рынки.

\footnotetext{
1 Термин «среда» в данном контексте применяется нами для обозначения совокупности базовых условий функционирования и развития е-бизнеса. Степень ее благоприятствования определяется не только условиями (возможностями), но и полноценно сформированными системами, позволяющими наиболее эффективно использовать имеющиеся условия.
} 
Существенная доля произведенной IT- продукции и услуг приходится на разработку программного обеспечения и консультирование в этой области (85\%). Основная часть компаний являлись разработчиками программного обеспечения на заказ. Вся создаваемая в результате реализации такого контракта интеллектуальная собственность была собственностью заказчика, что не стимулирует к развитию собственный рынок.

Любопытны с точки зрения направлений возможностей функционирования е-бизнеса интересы в области использования информационных технологий у организаций (рис. 1).

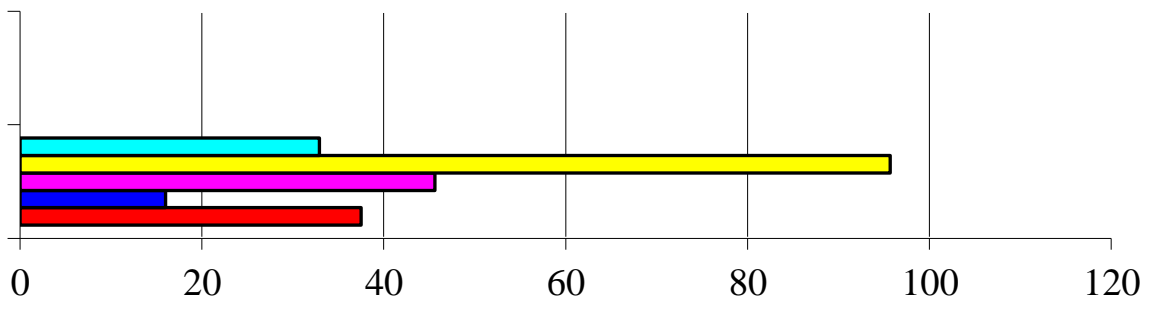

口получение доступа к другим финансовым услугам

口осуществление банковских операций

口пдписка к электронным ресурсам на платной основе

口 поставка электронной продукции

口получение электронной продукции

Рис. 1. Виды электронных услуг, востребованные организациями [10]

Получение электронной продукции (услуг) занимает около 38\%, поставка ее отечественными производителями в пределах 16\%.

Население более активно и открыто е-рынку, практически каждый 3-й потребитель из 10 покупает через е-сеть товары и услуги. Активно расширяется сеть электронных торговых площадок.

Следует учитывать данные тенденции в экономике, так как предпринимательская деятельность приобретает новые организационные формы. Естественно, возникновение нового нетрадиционного бизнеса порождает новые проблемы организации налогообложения.

Одной из наиболее существенных проблем в определении налоговых правил для электронного бизнеса является формирование такого налогового законодательства, которое могло бы гибко реагировать на вызовы цифровой экономики. Наиболее актуальными становятся следующие аспекты:

- установление базовых принципов налогообложения электронной экономической деятельности;

- законодательное закрепление видов электронного бизнеса;

- определение объекта обложения;

- определение плательщика (резидентства);

• осуществление налогового контроля в сфере электронной деятельности. 
Налогообложение опосредует происходящие изменения в предпринимательской деятельности. В связи с этим установление базовых принципов электронной экономической коммерции определяет направления разработки модели налогообложения доходов от электронного бизнеса.

Выбранная модель налогообложения базируется на праве каждого государства применять свои правила и нормы налогообложения электронной предпринимательской деятельности.

Представляется принципиально важным выбор позиции государства в организации налогообложения цифрового бизнеса. И здесь и юристы и экономисты предлагают два диаметрально разных подхода к этому вопросу:

1. Устранение злоупотреблений как со стороны компаний, так и со стороны юрисдикций, в том числе в рамках BEPS.

2. Включение в налоговую конкуренцию за электронный бизнес.

Республика Беларусь делает попытки адаптировать налоговое законодательство к специфике цифровой трансформации бизнеса с учетом соблюдения фискальных интересов, а также предоставляя достаточно широкий спектр налоговых льгот и преференций [11].

На текущий момент с достаточной долей условности можно выделить следующие виды деятельности, имеющие свои отличия в налогообложении:

- предоставление электронных услуг физическим лицам Республики Беларусь нерезидентами;

- деятельность резидентов Парка высоких технологий (ПВТ);

- осуществление электронной торговли;

- деятельность в сфере производства ИКТ и оказания электронных услуг резидентами Республики Беларусь.

Рассмотрим их подробнее.

Налогообложение электронных услуг нерезидентов. Беларусь с 2018 г. вслед за европейскими странами законодательно закрепила особый механизм налогообложения электронных услуг. Такой подход является достаточно распространенным в мировой практике, в соответствии с ним электронные услуги (цифровые продукты) подлежат налогообложению НДС по месту нахождения покупателя. На основании этого нерезиденты, предоставившие такие услуги физическим лицам на территории республики, являются плательщиками НДС. Налоговые обязательства не зависят от величины полученных доходов и распространяются на всех иностранных субъектов, оказывающих интернет-услуги.

Такие нерезиденты-организации обязаны еще до начала осуществления деятельности стать на налоговый учет в налоговых органах Беларуси. Процедура регистрации плательщика предусматривает, в свою очередь, представление в электронной форме налоговых деклараций и уплату НДС. С этой целью создан специальный онлайн-сервис, где в доступной форме через личный кабинет нерезидент может осуществить все предусмотренные законодательством процедуры. 
В соответствии с законодательством такие услуги облагаются НДС в случае, если получателем является физическое лицо на территории Республики Беларусь. Проблема заключается в сложности четкого определения получателя и его местонахождения. В связи с этим предусмотрено выполнение хотя бы одного из перечисленных условий:

- местом фактического нахождения получателя является Беларусь;

- местом нахождения кредитной организации, где открыт счет для оплаты услуг, или оператора электронных денежных средств, через которых осуществляется оплата услуг, является Беларусь;

- сетевой (IP) адрес устройства получателя, расплатившегося с нерезидентом, зарегистрирован в Беларуси;

- международный код страны телефонного номера, используемого для приобретения или оплаты услуг, принадлежит Беларуси.

В случае если такие цифровые продукты приобретаются белорусскими компаниями и индивидуальными предпринимателями (B2B), то сохраняется прежний порядок уплаты НДС, предполагающий взимание НДС через субъектов - налоговых агентов.

Действие законодательства распространяется на такие услуги в электронной форме, как софт, игры, базы данных, электронные книги, музыка и видео, реклама, размещение коммерческих предложений, поиск и отбор онлайн-данных, поиск потенциальных покупателей, торговые площадки, присутствие в сети, администрирование интернет-ресурсов, обращение информации, вычислительные мощности, домены и хостинг, поисковики, статистика.

Есть ряд освобождений от налогообложения НДС электронных услуг. Например, когда доставка цифрового продукта при заказе через сеть Интернет осуществляется без использования сети Интернет. В случае если реализация программного обеспечения, компьютерных игр, баз данных и др. производится на материальных носителях. Не облагаются НДС консультации по электронной почте, услуги по предоставлению доступа к сети Интернет и др.

Плательщиками налога являются как иностранные компании, так и белорусские субъекты хозяйствования в случаях, если они являются посредниками при оказании электронных услуг и непосредственно участвуют в расчетах с физическими лицами за указанные услуги..

При взимании налога применяется стандартная ставка в 20\%. Перечень зарегистрированных организаций-нерезидентов размещен на сайте МНС в электронном сервисе «е-НДС». На сегодняшний момент зарегистрировано более 50 организаций-нерезидентов. Среди них такие крупные иностранные организации, как Airbnb Ireland Unlimited Company, Amazon Services LLC, Apple Distribution International, Booking.COM B.V., Facebook Technologies Ireland Limited, Google Commerce Limited, Uber ML B.V., Viber Media Sarl и др.

Нововведение дало неплохой бюджетный эффект: полученные доходы превысили расходы по организации введения и уплаты налога. По итогам 
2018 г. зарубежными компаниями - поставщиками электронных услуг уплачено НДС (по предварительным оценкам) на сумму около 4 млн долл. [12].

Налогообложение резидентов ПВТ представляет специальный правовой режим с чрезвычайно льготным налогообложением и большим спектром правовых преимуществ перед обычным бизнесом. Наряду с деятельностью компаний ИТ-индустрии по разработке и обслуживанию ПО, резиденты имеют право осуществления бизнеса в области биотехнологий, медицины, авиационных и космических технологий, системы беспилотного управления транспортом, осуществления операций с криптовалютами и ICO, организации киберспорта, биржи криптовалют и др. Они также имеют право осуществлять майнинг и иную деятельность с использованием токенов, включая создание и размещение собственных токенов.

Правовые преимущества представлены упрощенным визовым режимом для привлекаемых квалифицированных зарубежных работников, либерализацией контрольной деятельности и упрощением документооборота. Резиденты парка вправе проводить внешнеторговые операции без учета ограничений, установленных законодательством Республики Беларусь по срокам и способам их завершения, заключать их в электронном виде с использованием Интернета, а также совершать операции с электронными деньгами без ряда ограничений. В качестве новаций, соответствующих профилю Парка, резиденты наделены правом совершения сделок посредством смарт-контрактов ${ }^{1}$.

Налоговые льготы резидентов ПВТ в обобщенном виде представлены в табл. 2.

\section{Таблица 2. Налоговые льготы резидентов ПВТ [13]}

\begin{tabular}{l|l}
\hline $\begin{array}{l}\text { Налог на при- } \\
\text { быль }\end{array}$ & $\begin{array}{l}\text { Освобождаются от уплаты налога на прибыль. По непрофильной } \\
\text { деятельности (по доходам резидентов ПВТ в виде процентов, дохо- } \\
\text { дам от отчуждения долей в уставных фондах организаций и от реали- } \\
\text { зации ценных бумаг, дивидендам от источников за пределами Бела- } \\
\text { руси) применяется ставка 9\% }\end{array}$ \\
\hline $\begin{array}{l}\text { Ввозные тамо- } \\
\text { пенные }\end{array}$ & $\begin{array}{l}\text { Освобождается от уплаты НДС ввоз определенного технологического } \\
\text { оборудования в целях его использования для выполнения инвестици- } \\
\text { онных проектов в рамках разрешенных видов деятельности }\end{array}$ \\
НДС при ввозе & $\begin{array}{l}\text { Освобождаются от уплаты НДС обороты по реализации на террито- } \\
\text { рии РБ }\end{array}$ \\
\hline НДС & $\begin{array}{l}\text { Освобождается от уплаты НДС приобретение имущественных прав } \\
\text { на объекты интеллектуальной собственности; рекламных, маркетин- } \\
\text { говых, консультационных услуг; услуг по обработке информации }\end{array}$ \\
\hline $\begin{array}{l}\text { НДС при имте у нерези } \\
\text { дентов }\end{array}$ & $\begin{array}{l}\text { Применяется пониженная ставка 9\% } \\
\text { Подоходный }\end{array}$ \\
\hline
\end{tabular}

1 Смарт-контракт представляет собой программный код, предназначенный для функционирования в распределенной информационной системе в целях совершения и (или) исполнения сделок либо совершения иных юридически значимых действий автоматизированным путем. 


\begin{tabular}{|c|c|}
\hline Взносы в ФСЗН & $\begin{array}{l}\text { Используется уменьшение облагаемой базы. Взносы начисляются и } \\
\text { уплачиваются не с фактической заработной платы работника, а со } \\
\text { средней по стране, которая в несколько раз ниже уровня заработной } \\
\text { платы в белорусской ІТ-индустрии }\end{array}$ \\
\hline $\begin{array}{l}\text { Оффшорный } \\
\text { сбор }\end{array}$ & $\begin{array}{l}\text { Освобождаются от офшорного сбора: } \\
\text { - дивиденды при выплате их учредителям (участникам), зарегистри- } \\
\text { рованным в офшорных зонах; } \\
\text { - денежные средства, перечисляемые нерезидентам, зарегистриро- } \\
\text { ванным в офшорных зонах, за посреднические, маркетинговые и ре- } \\
\text { кламные услуги }\end{array}$ \\
\hline $\begin{array}{l}\text { Налогообложе- } \\
\text { ние дивидендов }\end{array}$ & $\begin{array}{l}\text { Применяется ставка налога (если более льготный режим не преду- } \\
\text { смотрен соглашениями об избежании двойного налогообложения): } \\
\text { для физических лиц в размере 9\%; для иностранных организаций в } \\
\text { размере } 5 \%\end{array}$ \\
\hline $\begin{array}{l}\text { Налог на дохо- } \\
\text { ды нерезиден- } \\
\text { тов }\end{array}$ & $\begin{array}{l}\text { Ставка } 0 \% \text { для доходов иностранных организаций от оказания рези- } \\
\text { дентам ПВТ услуг по обработке данных, веб-хостинга, рекламных, } \\
\text { посреднических и некоторых иных услуг, а также в отношении дохо- } \\
\text { дов в виде процентов и роялти }\end{array}$ \\
\hline $\begin{array}{l}\text { Земельный } \\
\text { налог и налог на } \\
\text { недвижимость }\end{array}$ & $\begin{array}{l}\text { Освобождение объектов на территории и границах ПВТ, за исключе- } \\
\text { нием сданных в аренду }\end{array}$ \\
\hline $\begin{array}{l}\text { Налогообложе- } \\
\text { ние операций с } \\
\text { токенами }\end{array}$ & $\begin{array}{l}\text { Освобождаются от налогообложения: обороты, прибыль резидентов } \\
\text { ПВТ от деятельности по майнингу, созданию, приобретению, отчуж- } \\
\text { дению токенов; доходы физических лиц от деятельности } \\
\text { по майнингу, приобретения (в том числе в порядке дарения), отчуж- } \\
\text { дения токенов за белорусские рубли, иностранную валюту, электрон- } \\
\text { ные деньги и (или) обмена на иные токены; обороты по отчуждению } \\
\text { токенов, в том числе иностранными организациями, не имеющими } \\
\text { в РБ постоянных представительств и не состоящими в связи с этим } \\
\text { на учете в налоговых органах республики, а также выручка } \\
\text { от отчуждения токенов путем их обмена на иные токены }\end{array}$ \\
\hline
\end{tabular}

Налогообложение электронной торговли. Широкое развитие в Беларуси получила доля интернет-торговли в интернет-магазинах и на интернет-аукционах и составила в розничном товарообороте более $3 \%$.

На начало 2018 г. в торговом реестре было зарегистрировано 16175 интернет-магазинов. За год количество интернет-магазинов в Беларуси увеличилось на 17,2\%. Из них 7963 открыли организации, 8212 - индивидуальные предприниматели [14].

Налогообложение электронной торговли практически не отличается от налогообложения офлайн торговли. Интернет-магазины, открытые юридическими лицами, могут работать, используя общую систему налогообложения или применять особый режим.

Активно в систему интернет-торговли стали включаться индивидуальные предприниматели. В соответствии с налоговым законодательством при осуществлении розничной торговли через интернет-магазин определенными товарами индивидуальный предприниматель может являться плательщиком единого налога. 
Индивидуальный предприниматель при ведении бухучета и наличии документов на все реализуемые товары вправе применять общую систему налогообложения с уплатой подоходного налога либо перейти на уплату налогов при упрощенной системе налогообложения.

С 2018 г. возобновилась упрощенная система налогообложения для предпринимателей, занимающихся розничной торговлей через интернетмагазины. В свое время ее отмена вызвала сокращение количества онлайнпродавцов и отток предпринимателей из е-commerce. Упрощенную систему налогообложения могут применять интернет-магазины, которые отвечают нескольким критериям:

1. Средняя численность работников не превышает 100 человек.

2. Размер валовой выручки нарастающим итогом - для перехода на УСН со следующего календарного года:

организациями - 1465565 руб.;

индивидуальными предпринимателями - 315000 руб.

Существуют ограничения на отдельные виды деятельности, для которых не применяется режим электронной торговли. Например: продажа подакцизной продукции; страхование, перестрахование и риелторская деятельность, деятельность, по которой применяются другие специальные режимы налогообложения: единый налог на вмененный доход, единый налог на сельхозпроизводителя; реализация ювелирных изделий из драгоценных металлов и камней и др.

Налогообложение производства ИКТ и электронных услуг, оказываемых резидентами Республики Беларусь.

Сектор ИКТ включает следующие виды экономической деятельности, объединенные в подотрасли:

производство - изготовление электронных элементов и плат; производство компьютеров и периферийного и коммуникационного оборудования; производство электронной бытовой техники и магнитных и оптических носителей информации;

торговля - оптовая торговля компьютерами, периферийным компьютерным оборудованием и программным обеспечением; оптовая торговля электронным и коммуникационным оборудованием и их частями;

услуги - издание компьютерных игр и программного обеспечения; деятельность в области проводной, беспроводной и спутниковой связи и прочей в сфере телекоммуникаций. Также включает производство и услуги в области компьютерного программирования и компьютерных технологий; управление компьютерными системами, обслуживание компьютерной техники, включая ремонт компьютеров, коммуникационного и периферийного оборудования. Сюда также относятся предоставление услуг по размещению информации, деятельность вебпорталов и пр.

Если вопросы налогообложения торговли рассмотрены выше, то что касается е-бизнеса в сфере услуг и производства, отметим следующее. 
Государство аккумулирует применение налоговых льгот в ПВТ как с целью привлечения инвестиций, так и с целью обеспечения и упрощения налогового контроля.

Конкретные меры по налоговому стимулированию производства ИКТ и электронных услуг, не вошедших в Парк, находятся в области стимулирования научной и научно-технической деятельности, производства высокотехнологичной и инновационной продукции.

Так, в соответствии с налоговым законодательством не взимается НДС со стоимости научно-исследовательских, опытно-конструкторских, опытно-технологических работ, зарегистрированных в государственном реестре, и имущественных прав на объекты промышленной собственности. Льгота применяется при реализации этих оборотов на территории Республики Беларусь.

Для стимулирования выпуска высокотехнологичных и инновационных товаров собственного производства применяется налоговая льгота в виде пониженной ставки налога на прибыль 10\%.

Таким образом, если производство ИКТ и электронных услуг соответствует этим параметрам, есть возможность применить льготу по НДС и налогу на прибыль.

\section{Выводы}

Активное развитие е-бизнеса предполагает необходимость организации эффективного национального налогообложения, учитывающего как фискальные интересы, так и возможности привлечения инвестиций за счет механизма налоговой конкуренции [15].

Специфика электронной экономической деятельности требует установления базовых принципов налогообложения для всех видов электронного бизнеса.

Создание специальных льготных условий налогообложения электронного бизнеса или предоставление правовых преференций представляется перспективным направлением развития налогового законодательства для электронного бизнеса.

\section{Литература}

1. Tapscott D. The Digital Economy: Promise and Peril in the Age of Networked Intelligence. New York, NY : McGraw-Hill, 1996.

2. Kling R., Lamb R. IT and Organizational Change in Digital Economies // Understanding the Digital Economy (E. Brynjolfsson, B. Kahin (eds)). Cambridge : MIT Press, MA, 2000. P. 295-324.

3. Mesenbourg T.L. Measuring the Digital Economy, US Bureau of the Census, Suitland. URL: https://www.census.gov/content/dam/Census/library/workingpapers/2001/econ/ umdigital.pdf

4. Bukh R., Heeks R. Defining, Conceptualising and Measuring the Digital Economy // Global Development Institute working papers. № 68. URL: https://diodeweb.files. wordpress.com/2017/08/diwkppr68-diode.pdf 
5. Begin your Digital Transformation (DX) Journey with IDC. URL: https://www.idc. com/promo/dxjourney/home

6. Интересные факты об интернет-торговле в 2019 году. URL: https://lemarbet.com/ razvitie-internet-magazina/interesnye-fakty-ob-internet-torgovle

7. Киреева Е.Ф. Трансформация предпринимательской деятельности в связи с развитием IT-отрасли: проблемы организации бизнеса и налогообложения // Вестник БДЭУ. 2017. № 6 (125). С. 13-20.

8. Беларусь в Индекс развития информационно-коммуникационных технологий. URL: http://www.scienceportal.org.by/upload/2018/Portal\%20news/Ranking/4.\%20ICT\% 20BY.pdf

9. Информационные технологии в Белоруссии. URL: http://www.tadviser.ru/index.php

10. Информачионное общество в Республике Беларусь. URL: http://www.belstat. gov.by/ofitsialnayastatistika/publications/izdania/public_compilation/index_7864

11. Киреева Е.Ф., Лукьянова И.А. Налоговые преференции как стимул повышения инвестиционной привлекательности Республики Беларусь // Вестник БДЭУ. 2015. № 6. C. $92-101$.

12. MHC рассчитывает получить \$4 млн от «налога на Google» в 2018 году. URL: https://www.belnovosti.by/ekonomika/mns-rasschityvaet-poluchit-4-mln-ot-naloga-nagoogle-v-2018-godu

13. Декрет № 8 от 21 декабря 2017 г. «О развитии цифровой экономики». URL: http://president.gov.by/ru/official_documents_ru/view/dekret-8-ot-21-dekabrja-2017-g-17716.

14. Розничная торговля. URL: http://www.belstat.gov.by/ofitsialnaya-statistika/realnysector-ekonomiki/vnytrennia-torgovlya/roznichnaya-torgovlya

15. Киреева Е.Ф. Налоговая реформа: необходимость, основные направления и меры по их реализации // Белорусский экономический журнал. 2018. № 4. С. 77-88.

\section{Taxation of Digital Business in Belarus: New Approaches and Stimulating Mechanisms}

Vestnik Tomskogo gosudarstvennogo universiteta. Ekonomika - Tomsk State University Journal of Economics. 2019. 46. pp. 279-290.

DOI: $10.17223 / 19988648 / 46 / 19$

Elena F. Kireyeva, Doctor of Economics, professor, head of the Department of Taxes and Taxation, Belarus State Economic University (Minsk, Belarus). E-mail: kireeva@yandex.ru Keywords e-business, e-services, taxation, e-market, taxation of e-services, High-Tech Park, tax incentives.

The article presents the problems of organizing business taxation in the context of the development of the e-market. The concept of e-business and the need to assess the capacity of the e-market in order to develop a strategy for the development of e-commerce and services are defined. The tax mechanisms of stimulating the activities in the field of ICT production and trade are summarized. The features of taxation of electronic services provided by non-residents in Belarus are studied. The tax and legal incentives for residents of the High-Tech Park (HTP) are analyzed. The options for the development of tax laws for electronic business are proposed.

\section{References}

1. Tapscott, D. (1996) The Digital Economy: Promise and Peril in the Age of Networked Intelligence. New York, NY: McGraw-Hill.

2. Kling, R. \& Lamb, R. (2000) IT and Organizational Change in Digital Economies. In: Brynjolfsson, E. \& Kahin, B. (eds) Understanding the Digital Economy. Cambridge, MA: MIT Press.

3. Mesenbourg, T.L. (2001) Measuring the Digital Economy. Suitland: US Bureau of the Census. [Online] Available from: https://www.census.gov/content/dam/Census/ library/workingpapers/2001/econ/ umdigital.pdf. 
4. Bukh, R. \& Heeks, R. (2017) Defining, Conceptualising and Measuring the Digital Economy. Global Development Institute working papers. 68. [Online] Available from: https://diodeweb.files. wordpress.com/2017/08/diwkppr68-diode.pdf.

5. IDC. (n.d.) Begin your Digital Transformation (DX) Journey with IDC. [Online] Available from: https://www.idc. com/promo/dxjourney/home.

6. Lemarbet.com. (2019) Interesnye fakty ob internet-torgovle v 2019 godu [Interesting facts about online trading in 2019]. [Online] Available from: https://lemarbet.com/razvitieinternet-magazina/interesnye-fakty-ob-internet-torgovle.

7. Kireeva, E.F. (2017) Transformatsiya predprinimatel'skoy deyatel'nosti v svyazi s razvitiem IT-otrasli: problemy organizatsii biznesa i nalogooblozheniya [Transformation of entrepreneurial activity in connection with the development of the IT industry: problems of business organization and taxation]. Vestnik BDEU. 6 (125). pp. 13-20.

8. Scienceportal.org.by. (2018) Belarus' $v$ Indeks razvitiya informatsionnokommunikatsionnykh tekhnologiy [Belarus in the Index of Development of Information and Communication Technologies]. [Online] Available from: http://www.scienceportal.org.by/ upload/2018/Portal\%20news/Ranking/4.\%20ICT\%20BY.pdf.

9. Tadviser.ru. (n.d.) Informatsionnye tekhnologii v Belorussii [Information technology in Belarus]. [Online] Available from: http://www.tadviser.ru/index.php.

10. Belstat.gov.by. (n.d.) Informatsionnoe obshchestvo $v$ Respublike Belarus' [The information society in the Republic of Belarus]. [Online] Available from: http://www.belstat.gov.by/ofitsialnaya-statistika/publications/izdania/public_compilation/ index_7864.

11. Kireeva, E.F. \& Luk'yanova, I.A. (2015) Nalogovye preferentsii kak stimul povysheniya investitsionnoy privlekatel'nosti Respubliki Belarus' [Tax preferences as an incentive to increase the investment attractiveness of the Republic of Belarus]. Vestnik BDEU. 6. pp. $92-101$.

12. Belnovosti.by. (2018) MNS rasschityvaet poluchit' \$4 mln ot "naloga na Google" $v$ 2018 god $u$ [The Tax and Duties Ministry expects to receive $\$ 4$ million from the "Google tax" in 2018]. [Online] Available from: https://www.belnovosti.by/ekonomika/mns-rasschityvaetpoluchit-4-mln-ot-naloga-na-google-v-2018-godu.

13. Republic of Belarus. (2017) Decree No. 8 of December 21, 2017 on the development of the digital economy. [Online] Available from: http://president.gov.by/ru/official_ documents_ru/view/dekret-8-ot-21-dekabrja-2017-g-17716. (In Russian).

14. Belstat.gov.by. (n.d.) Roznichnaya torgovlya [Retail]. [Online] Available from: http://www.belstat.gov.by/ofitsialnaya-statistika/realny-sector-ekonomiki/vnytrenniatorgovlya/roznichnaya-torgovlya.

15. Kireeva, E.F. (2018) Tax reform: necessity, main directions and measures of their implementation. Belorusskiy ekonomicheskiy zhurnal - Belarusian Economic Journal. 4. pp. 77-88. (In Russian). 